\title{
CHROMOSOME PAIRING IN AUTOTETRAPLOID BOMBYX FEMALES. MECHANISM FOR EXCLUSIVE BIVALENT FORMATION
}

\author{
by \\ SØREN W. RASMUSSEN and PREBEN B. HOLM \\ Department of Physiology, Carlsberg Laboratory, \\ Gamle Carlsberg Vej 10, DK-2500 Copenhagen Valby
}

Keywords: Synaptonemal complex, homologous pairing, nonhomologous pairing, pachy-
tene, disjunction

Meiosis in tetraploid Bombyx mori oocytes has been analyzed by three dimensional reconstructions of 1 mid zygotene, 7 early pachytene and 11 mid-late pachytene nuclei. The general pattern of chromosome pairing was found to be essentially similar to that of diploid oocytes. The zygotene stage is recognizable by incomplete pairing and a distinct chromosome bouquet, early pachytene by complete or almost complete pairing and a distinct bouquet and mid-late pachytene by dissolution of the bouquet followed by release of chromosome ends from their attachment sites on the nuclear envelope. At early pachytene the nuclei contained 5-12 quadrivalents, 0-7 univalents, $0-3$ trivalents and $27-44$ bivalents. The corresponding figures for mid-late pachytene were $0-2$ quadrivalents, $0-3$ univalents, $0-2$ trivalents and $48-56$ bivalents. The remarkable decrease in the number of quadrivalents and the corresponding increase in the number of bivalents between early and mid-late pachytene is the result of a correction of the zygotene pairing. In the absence of crossing over and chiasma formation, the pairing of the randomly located leptotene chromosomes into the maximal number of bivalents consists thus of two phases: 1) A specific zygotene pairing with synaptonemal complex formation restricted to homologous chromosome regions and 2) a correction of irregularities in this pairing by partial dissolution of the central region of the complex succeeded by or coinciding with a second round of synaptonemal complex formation, permitting also nonhomologous pairing. It is suggested that in organisms with crossing over and chiasma formation the correction process is impeded by the occurrence of crossovers.

\section{INTRODUCTION}

The classical concept of chromosome pairing during meiotic prophase as a highly specific process has been substantiated by a number of investigations using the technique of serial sectioning and three dimensional reconstruction. These studies have shown that at pachytene, homologous chromosomes are held in register by a continuous synaptonemal complex from telomere to telomere revealing an apparently specific site-to-site matching of homologous regions. Both light and electron microscopical studies agree in that the number of irregularities is surprisingly low $(2,4,6,9,13,14,16,22$, 33). Furthermore, it has been demonstrated that prior to the onset of pairing, homologous chromosomes are either located at random in the nucleus $(11,12,22,25)$ or in separate nuclei $(4$, 
$32,33)$ the only exception being organisms with a permanent somatic pairing of homologous chromosomes.

An apparent contradiction to the concept of a highly specific and regular zygotene chromosome pairing and synaptonemal complex formation is the observation of nonhomologous pairing of chromosomes or chromosome segments with structurally normal synaptonemal complexes as is the case in haploids (10), in hybrids (20) and in organisms heterozygous for chromosomal rearrangements $(8,9,14,21)$.

This contradiction could be obviated as a result of the analysis of triploid Bombyx oocytes (24). In triploid Bombyx oocytes chromosome pairing during zygotene is strictly homologous resulting at early pachytene in homologously paired bivalents and trivalents in addition to univalents. Later in pachytene, trivalents are absent whereas many univalents are now nonhomologously paired either by folding back on themselves or as nonhomologous associations of 2, 3 or 4 chromosomes. These observations require the occurence of a correction process in which the trivalents formed during the specific pairing phase at zygotene are first reorganized into bivalents and univalents through a dissolution and reassembly of the synaptonemal complex. Thereafter, in a second round of synaptonemal complex formation, which does not require homology, nonhomologous associations can form. It was proposed (24) that this correction is only possible throughout the entire genome in the absence of crossing over and chiasma formation as is the case in Bombyx females (29, $30)$.

A recent analysis of chromosome pairing and synaptonemal complex formation in human spermatocytes heterozygous for a reciprocal translocation $(14,25)$ likewise demonstrated a homologous phase of pairing at zygotene followed by a nonhomologous phase of pairing at mid-pachytene. The pairing of the involved segments was in all early pachytene nuclei strictly homologous resulting in the formation of a quadrivalent whereas at mid-late pachytene, one of the four nuclei analyzed revealed extensive nonhomologous pairing of the involved chromosomes and their homologues. This indicates that correction is also possible if crossing over has not or not yet occurred in the chromosomes involved (14). Similar results were obtained by Moses (21) in mice heterozygous either for a tandem duplication or for an inversion. In both cases, pairing was strictly homologous at early pachytene resulting in a duplication loop or an inversion loop. In late pachytene, however, the duplication loop could not be recognized and the pairing of the inverted segment was nonhomologous, both cases revealing apparently normal bivalents with continuous synaptonemal complexes throughout their lengths.

The molecular mechanisms responsible for bringing together the homologues as well as the mechanisms by which a precise pairing is achieved is still largely unknown. It has been especially difficult to understand how synapsis can proceed in organisms with more than one initiation site for synaptonemal complex formation per bivalent (cf. 11, 12, 32, 33) without the occurrence of extensive interlocking of bivalents. The low frequency of interlocking and other irregularities at pachytene and later meiotic stages has inspired several authors to postulate a preleptotene alignment of homologous chromosomes $(3,7,19)$.

On the contrary, in diploid Bombyx oocytes, interlockings are frequent at late zygotene but absent at pachytene (22). It has therefore been proposed $(24,26)$ that in the absence of stabilizing crossovers in the region between the interlocked segment and the nuclear envelope, interlockings can resolve by dissolution of the synaptonemal complex, movement of the interlocked lateral component or bivalent relative to the interlocking bivalent followed by a reformation of the synaptonemal complex. If the pairing is stabilized by crossovers, interlockings have to be resolved by breakage and reunion of lateral components or synaptonemal complexes as indeed is observed in human spermatocytes (25): At late zygotene $60 \%$ of the nuclei contained one or more interlockings whereas only $4.8 \%$ did so at early pachytene. At late zygotene, several breaks of lateral components or synaptonemal complexes could be identified. At early pachytene, breaks were rare suggesting that the majority of the breaks present at late zygotene had healed by reunion of the broken ends.

Because of the absence of crossing over the two phases of pairing would predict more or less complete bivalent formation towards the end of 
pachytene in autotetraploid oocytes of Bombyx. Preliminary electron microscopical analysis of tetraploid oocytes (26) have demonstrated the presence of quadrivalents at early pachytene and an absence of quadrivalents at mid-late pachytene. This investigation describes in detail the events which by the end of pachytene result in an almost regular bivalent formation.

\section{MATERIALS AND METHODS}

The material used in the present study was kindly provided by the late professor B. L. Astaurov, Institute of Developmental Biology, Academy of Sciences USSR, Moscow. The tetraploid females were produced by thermal activation of fertilized eggs and were maintained as parthenogenetic clones by thermal activation of dissected eggs as described by Astaurov (1) and VEREISKAYA (31).

The procedure for removing the ovaries and their subsequent fixation, dehydration and embedding has been described previously (22). Thick sections $(2-4 \mu \mathrm{m})$ were cut and examined in the light microscope in order to identify regions of the ovary containing nuclei in the desired stage of development. Series of thin sections were cut, photographed at a primary magnification of 4-5,000 times and reconstructed as described by Holm and Rasmussen (13). The projected lengths were measured and the real lengths calculated with the aid of a Hewlett Packard digitizer (HP 9864A) and calculator (HP 9825A).

The results are based on complete reconstructions of 1 mid zygotene nucleus, 7 early pachytene nuclei and 11 mid-late pachytene nuclei.

\section{RESULTS}

\subsection{General aspects}

The three prophase stages described in the present report were distinguished by the following criteria: 1) Zygotene: by the incomplete chromosome pairing and a pronounced chromosome bouquet. 2) Early pachytene: by a distinct chromosome bouquet and complete chromosome pairing, except for short regions in some of the multivalents at the sites of pairing partner exchange. 3) Mid-late pachytene: by complete chromosome pairing, the only unpaired lateral components being those of univalents, and by an even distribution of the bivalents throughout the nucleus. Towards the end of pachytene the telomeres are released from the nuclear envelope.

The general morphology of the cells and the nuclei is similar to that of di- and triploid oocytes $(22,24)$ and will not be described again. Also the ultrastructure of the synaptonemal complex is indistinguishable from that of di- and triploid oocytes. The lateral components frequently appear tripartite with two dense subelements bordering an electron transparent region. The width of the central region is $70-80 \mathrm{~nm}$ compared to a width of $100 \mathrm{~nm}$ in Bombyx males (unpublished observation by HoLm and RASMUSSEN).

Studies of diploid spermatocytes - in which crossing over occurs $(29,30)$ - have demonstrated the presence of electron dense nodules, socalled recombination nodules (5), associated with the central region of the complex, whereas such nodules have not been found in di-, tri- and tetraploid oocyte nuclei.

As previously noted (22), only two chromosomes can be identified unequivocally by morphological markers: the longest chromosome, number 1 , by a knob which is present from zygotene through pachytene and chromosome 2 by the nucleolus organizer region. The remaining 26 chromosomes can only be classified according to length. As a large fraction of the chromosomes is of equal length and the length of a particular chromosome (i.e., chromosomes 1 or 2) is found to vary among different nuclei, an unequivocal identification of individual chromosomes other than chromosomes 1 and 2 is impossible.

\subsection{Chromosome pairing}

\subsubsection{Zygotene}

The complete reconstruction in Figure la illustrates the general organization of chromosomes at mid zygotene. All telomeres are attached to the inner membrane of the nuclear envelope, the polarized distribution of the attachment sites giving rise to a chromosome bouquet. The same nucleus is depicted in six separate reconstructions (Figures $\mathrm{lb}-\mathrm{g}$ ). Chromosome pairing and synaptonemal complex 


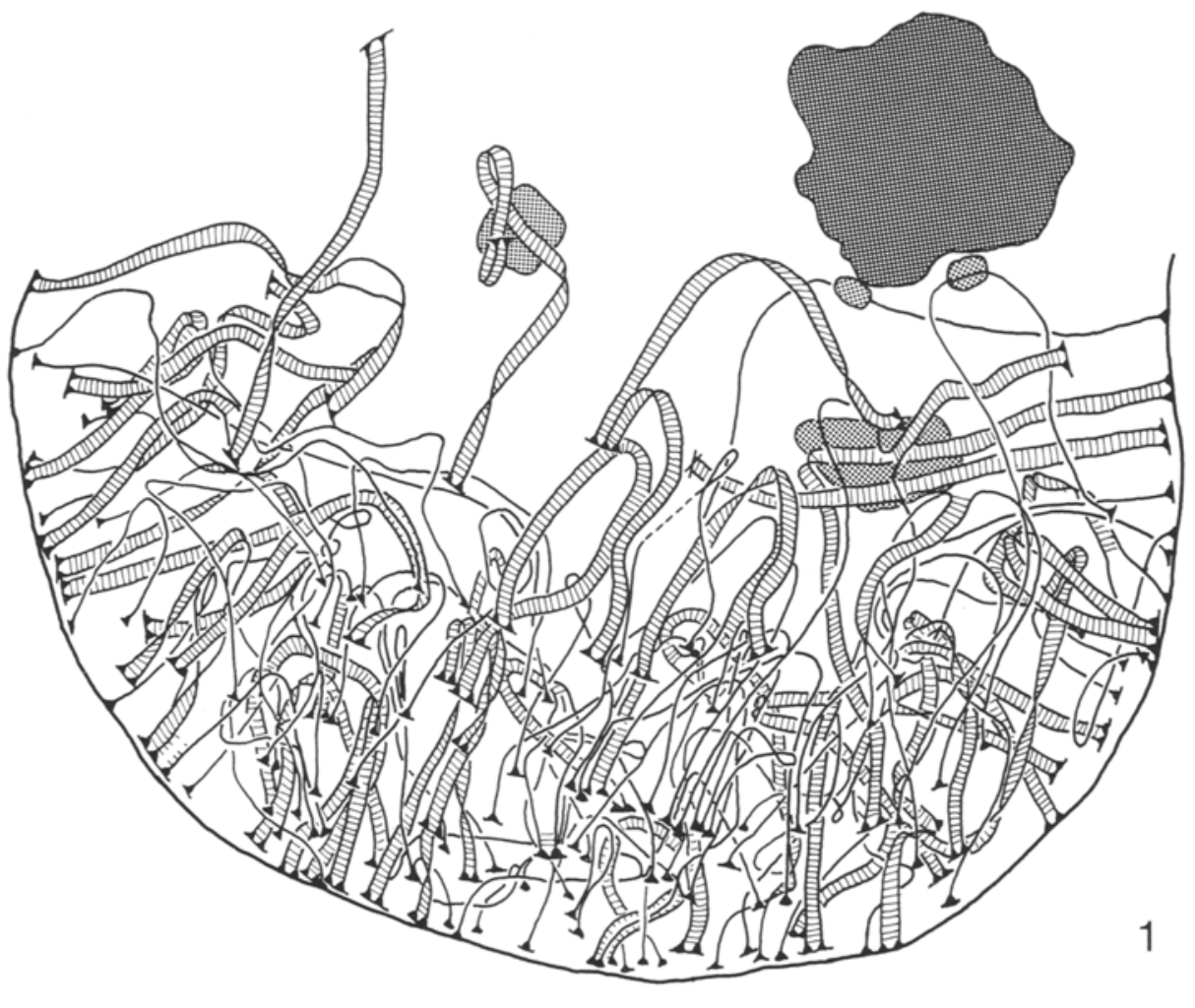

formation are highly asynchronous: Twentytwo bivalents are completely paired each with a continuous synaptonemal complex from telomere to telomere. Synaptonemal complex formation is initiated but not yet completed in 18 chromosome pairs while the remaining 16 chromosome pairs are present as univalents. In addition, two chromosome fragments have been identified, both of them with only one of the ends attached to the nuclear envelope. Similar fragments have not been found in other tetraploid nuclei, while fragments were regularly seen in triploid oocytes.

Chromosome pairing and synaptonemal complex formation appear to follow the same pattern as that described in diploid and triploid females $(22,24)$. Homologous chromosomes are not prealigned prior to the onset of pairing as judged by the relative location of homologues at mid zygotene (cf. the chromosomes carrying the nucleolar organizer regions in Figures $1 \mathrm{c}$ and 1d). Reconstructions of triploid oocytes at early pachytene (24) have demonstrated that in most cases, the three homologous telomeres are attached to the nuclear envelope in close proximity. Association of homologous telomeres is also observed in tetraploid oocytes as illustrated in Figure le where a bivalent and a univalent of approximately the same length are attached to the nuclear envelope close to each other. Likewise, two bivalents with nearly identical length and with closely associated telomeres can be recognized in Figures If and $g$.

Synaptonemal complex formation in diploid and triploid oocytes was observed to be initiated exclusively from the telomeres. In the present nucleus, however, two cases of interstitial initiation of synaptonemal complex formation were revealed (Figures 1d and g) thus demonstrating that in female Bombyx as in other organisms $(11,12,25,32,33)$, initiation of synaptonemal complex formation can take place interstitially.

A short stretch of double synaptonemal 

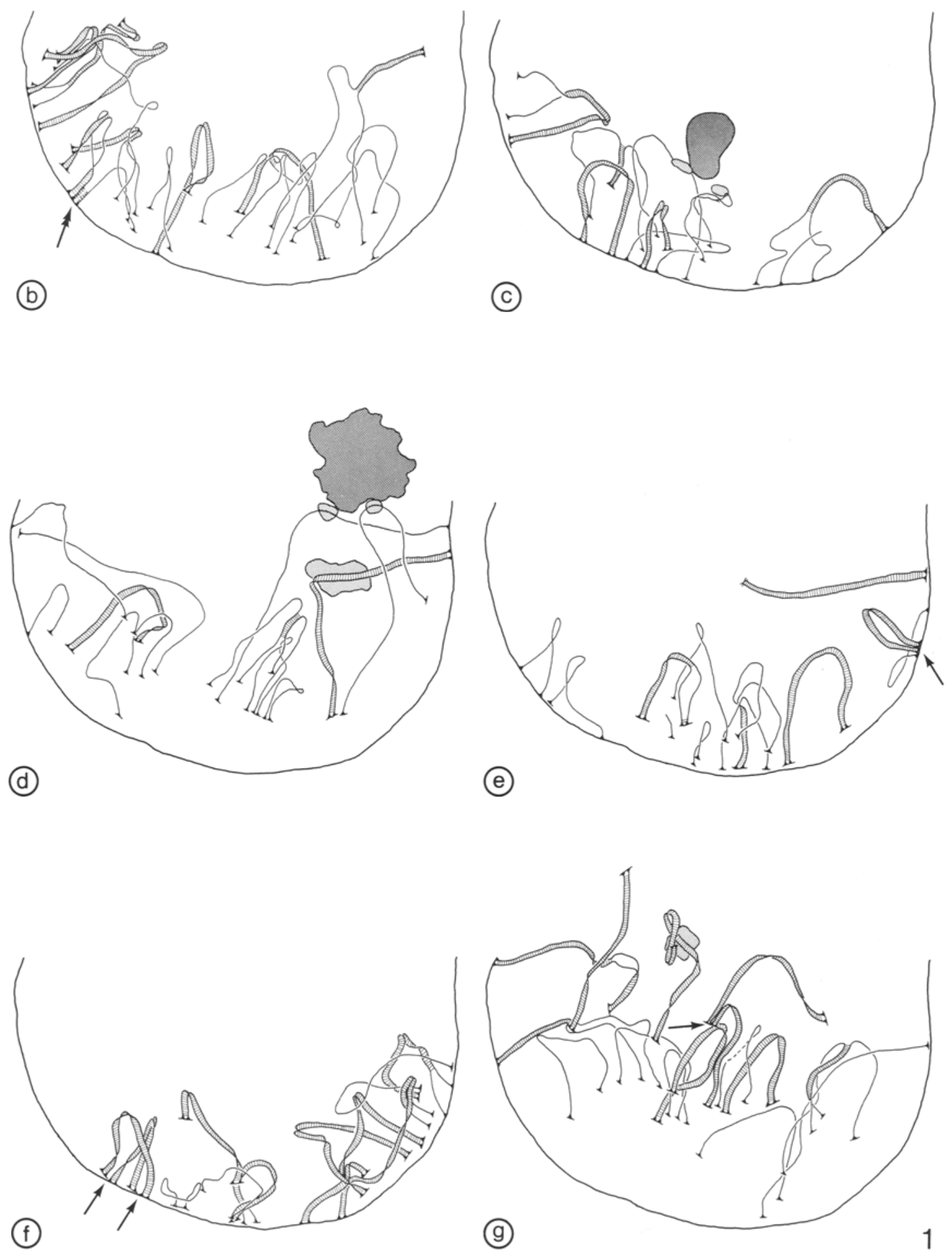

Figure 1. Figure la shows a complete reconstruction of a mid zygotene nucleus and Figures $l b-g$ the details of chromosome pairing in this nucleus. The nucleolus is shown with a dark hatching, knobs and nucleolus organizer regions with an intermediate hatching. Single arrows denote associations of homologous telomeres and the double arrow a double synaptonemal complex, see text. 

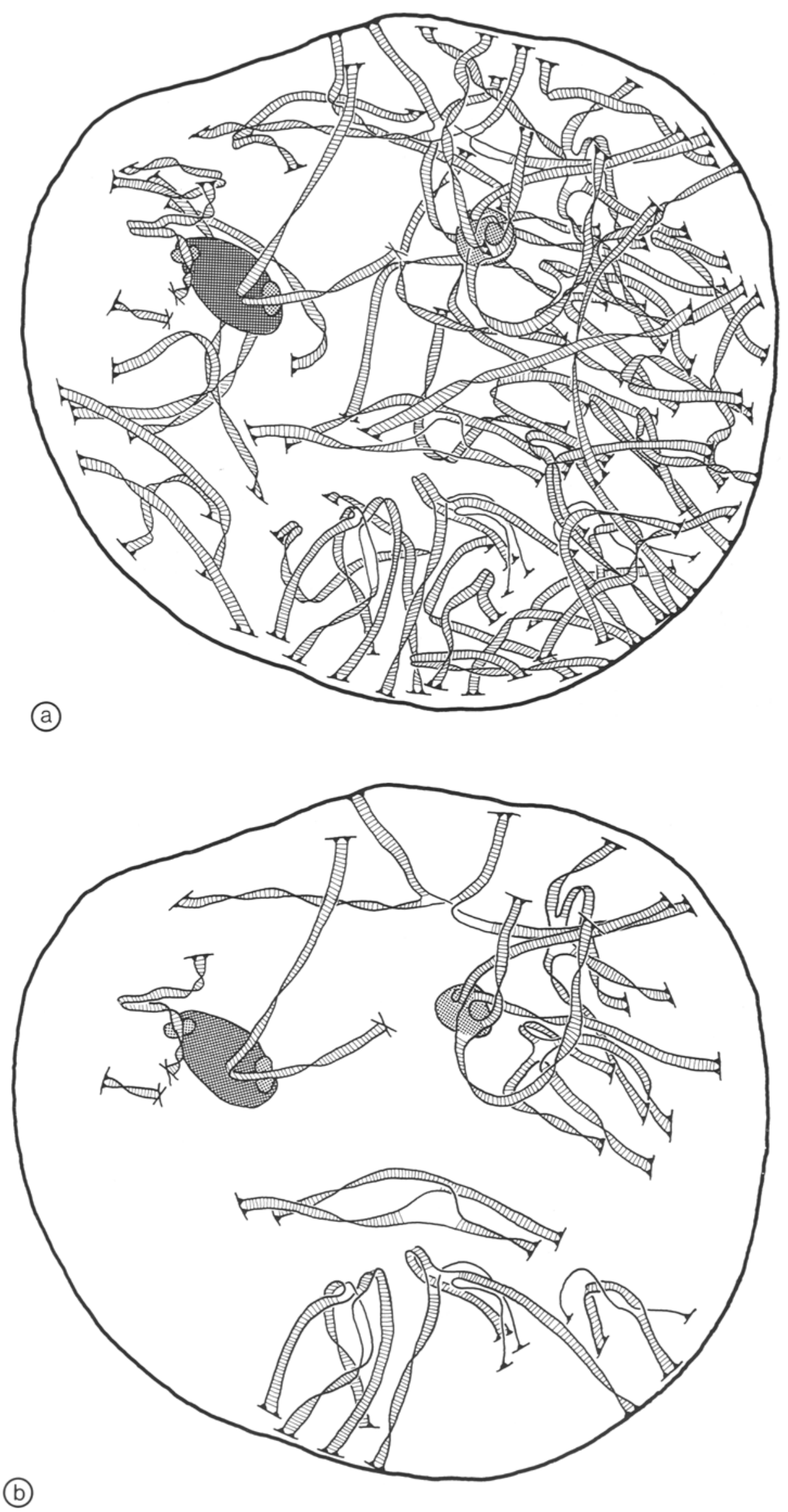
complex is shown in Figure lb. The central region of one of the complexes has not attained the normal ultrastructural characteristics of completed synaptonemal complexes. Similar double complexes have been found in triploid Bombyx females, one or both of the central regions being less elaborate than that of fully formed central regions.

\subsubsection{Early pachytene}

The characteristics of the early pachytene stage in the tetraploid Bombyx females are illustrated by the complete reconstruction shown in Figure 2. The telomeres are attached to the nuclear envelope giving rise to a distinct chromosome bouquet. In several cases, shift of pairing partner has taken place leading to formation of associations of three or four chromosomes. The reconstruction in Figure $2 b$ includes seven associations of four chromosomes and one association of three chromosomes.

An important problem in the analysis of the pairing pattern seen in early pachytene is to decide whether pairing is between homologous regions only or whether nonhomologous pairing also takes place during zygotene. Evidence from di- and triploid Bombyx females $(22,24)$ as well as from other organisms $(12,14,25,33)$ have demonstrated that chromosome pairing during zygotene is exclusively confined to homologous regions. In tetraploid Bombyx females, the distinction between homologous and nonhomologous pairing is hampered by the fact that only chromosomes 1 and 2 can be identified with certainty. As described below, these chromosomes frequently form quadrivalents, and nonhomologous associations involving these chromosomes have not been found. For the remainder of the chromosomes, the classification of multiple associations is based on the degree of similarity in length. Three types of associations are, however, entirely or in part nonhomologous: 1) Three chromosomes paired completely with the synaptonemal complex in Y configuration. 2) Chromosomes of different length combined with a synaptonemal complex, e.g. in cases where one lateral component extends beyond the paired region. 3) Foldback pairing of a univalent.

The reconstruction shown in Figures $3 a-d$ illustrates the different types of associations in an early pachytene nucleus. The lengths of the bivalents, univalents and the individual chromosomes of the multiple associations are given in Tables Ia and Ib. The nucleus contains 27 bivalents (Figure 3a), 12 associations of 4 chromosomes, 3 associations of 3 chromosomes and 1 univalent (Figures $3 b-d$ ). Chromosomes 1 and chromosomes 2 both form quadrivalents. As shown in Table Ib, a $14 \%$ difference in absolute length is encountered between the longest and the shortest chromosome 1, the corresponding figure for chromosome 2 being $16 \%$. These differences may in part be attributed to deformation of the lateral components at the point of pairing partner exchange caused by difficulties in quadrivalent formation. The remainder of the quadruple associations, i.e., chromosome numbers $3,7,9,11,14,15,16,18$ and 26 have all been classified as quadrivalents on the basis of similarity in lengths (Table Ib), the length differences being comparable to those observed for chromosomes 1 and 2. In addition, the telomeres assumed to be homologous are generally located close to each other (e.g., quadrivalents $9,14,15,16,18,26)$. Based on the same criteria, the triple association of chromosomes 4 in Figure $3 \mathrm{~b}$ is a trivalent.

Three cases of nonhomologous associations have been observed in this nucleus. The pairing of chromosomes 5Aa, 5Ab and 28Aa (Figure $3 \mathrm{~b}$ ), as well as of $20 \mathrm{Ba}, 20 \mathrm{Bb}$ and $28 \mathrm{Ab}$ (Figure 3d) results in $\mathrm{Y}$ shaped configurations in which the pairing is in part nonhomologous. Finally, the short stretch of synaptonemal complex between the lateral components of two interlocked bivalents in Figure 3c (chromosomes 21)

Figure 2. Reconstruction of an early pachytene nucleus (number 18). Figure 2 a shows a complete reconstruction illustrating the chromosome bouquet. The nucleus contains seven quadrivalents and one trivalent, which are shown together with the nucleolus organizing bivalent in Figure 2b. In one of the nucleolus organizing bivalents, the synaptonemal complex is interrupted over a distance of $0.5 \mu \mathrm{m}$ (the broken ends are denoted by crosses). One pair of telomeres of the second organizer bivalent are free in the nucleoplasm (denoted by a cross). The four chromosomes 1 form a quadrivalent, the shift of pairing partners occurring inside the knob. 
S. W. Rasmussen \& P. B. Holm: Chromosome pairing in Bombyx

(a)
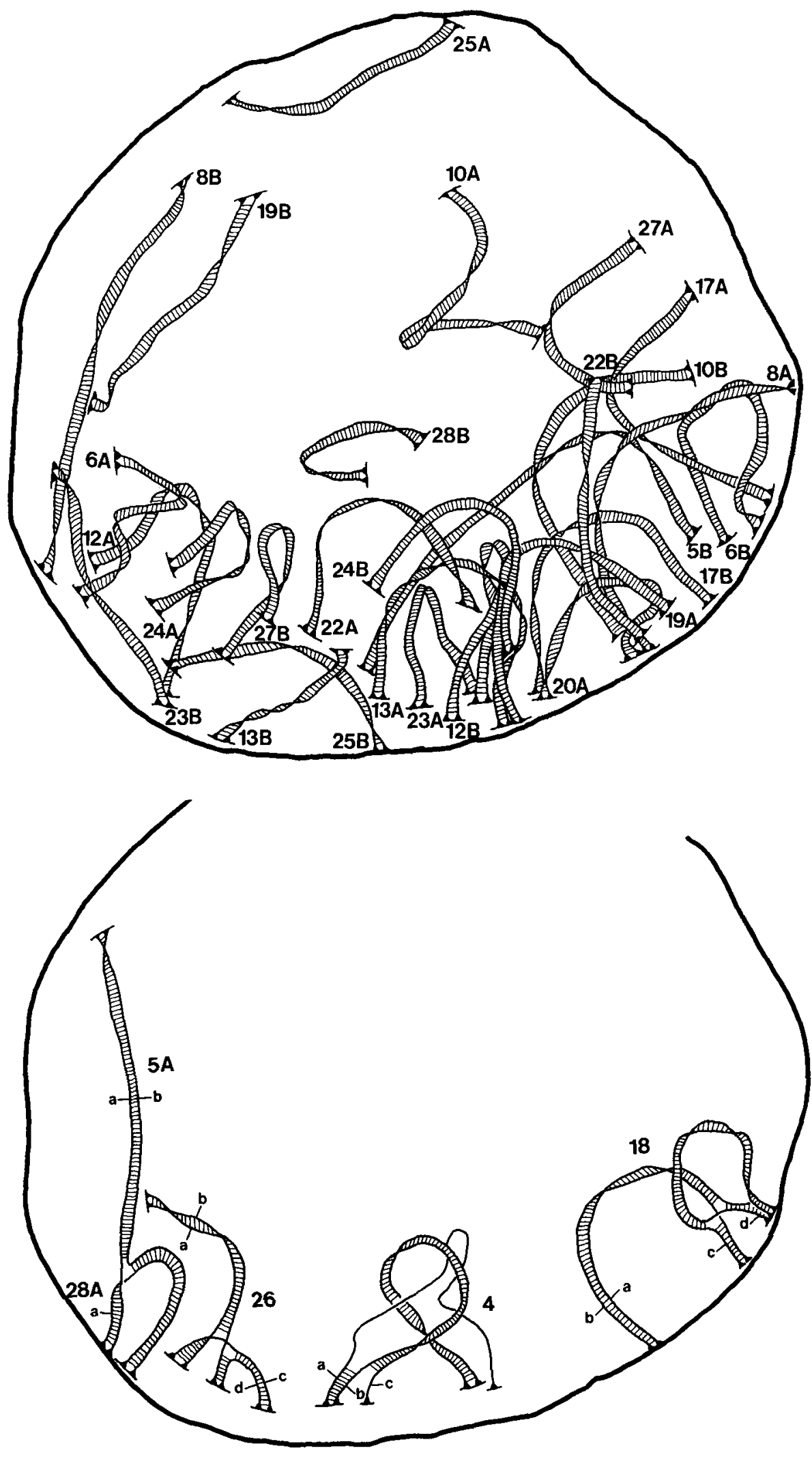
S. W. Rasmussen \& P. B. Holm: Chromosome pairing in Bombyx

(C)
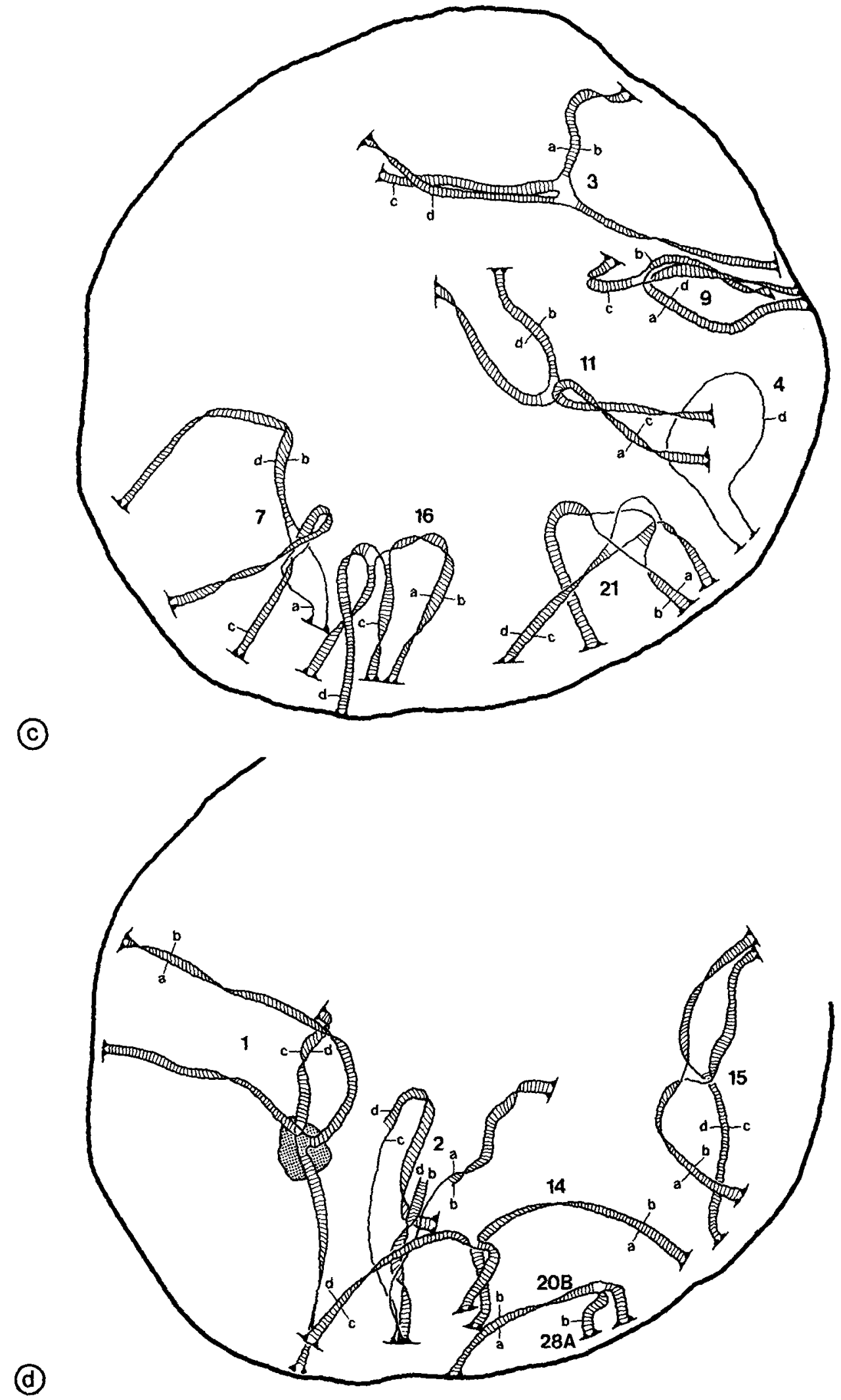
Table I a

Synaptonemal complex length of the 27 bivalents of nucleus 19. (See also Table $1 \mathrm{~b}$ and Figure $3 \mathrm{a}$ ).

\begin{tabular}{cccc}
$\begin{array}{c}\text { Bivalent } \\
\text { number }\end{array}$ & $\begin{array}{c}\text { Synaptonemal complex } \\
\text { length }(\mu \mathrm{m})\end{array}$ & $\begin{array}{c}\text { Bivalent } \\
\text { number }\end{array}$ & $\begin{array}{c}\text { Synaptonemal complex } \\
\text { length }(\mu \mathrm{m})\end{array}$ \\
\hline $5 \mathrm{~B}$ & 6.7 & $19 \mathrm{~A}$ & 4.9 \\
& & $19 \mathrm{~B}$ & 4.8 \\
$6 \mathrm{~A}$ & 6.5 & $20 \mathrm{~A}$ & 4.8 \\
$6 \mathrm{~B}$ & 6.1 & & \\
& & $22 \mathrm{~A}$ & 4.7 \\
$8 \mathrm{~A}$ & 6.0 & $22 \mathrm{~B}$ & 4.6 \\
$8 \mathrm{~B}$ & 5.9 & $23 \mathrm{~A}$ & 4.6 \\
$10 \mathrm{~A}$ & 5.6 & $23 \mathrm{~B}$ & 4.6 \\
$10 \mathrm{~B}$ & 5.5 & $24 \mathrm{~A}$ & 4.4 \\
$12 \mathrm{~A}$ & 5.5 & $24 \mathrm{~B}$ & 4.4 \\
$12 \mathrm{~B}$ & 5.3 & & \\
$13 \mathrm{~A}$ & 5.2 & $25 \mathrm{~A}$ & 3.9 \\
$13 \mathrm{~B}$ & 5.2 & $25 \mathrm{~B}$ & 3.8 \\
$17 \mathrm{~A}$ & & $27 \mathrm{~A}$ & 3.7 \\
$17 \mathrm{~B}$ & 5.0 & $27 \mathrm{~B}$ & 3.6 \\
& 4.9 & $28 \mathrm{~B}$ & 3.3 \\
\hline
\end{tabular}

appears to be between nonhomologous chromosome regions. As judged by their similarity in length, the two partially paired bivalents are homologous. The interpretation of the short interstitial stretch of synaptonemal complex as being between nonhomologous regions is illustrated in Figures 4 and 5. As shown in Figure $3 \mathrm{~d}$, the lateral components of chromosomes $2 \mathrm{~b}$ and $2 \mathrm{~d}$ are discontinuous over a distance of 1.0 $\mu \mathrm{m}$ in the nucleolus organiser region. This may be due to breakage of these two lateral components, or may reflect incomplete laterel component organization in this region. Lateral components are frequently indistinct or completely absent in the nucleolus organizer region in tetraploid as well as in di- and triploid oocytes (22, 24).
A summary of the results on chromosome pairing in early pachytene is shown in Table II. A mean number of 2.0 univalents, 36.7 bivalents, 0.7 associations of three chromosomes and 8.4 associations of 4 chromosomes are present per nucleus. The relatively high frequency of univalents is to some extent a result of aneuploidy. As seen in Table II, only two nuclei contain the expected chromosome number of 112 while the remaining nuclei only contain 111 chromosomes.

The different types of quadrivalents, trivalents and associations of three and four chromosomes are shown in Table III. According to the criteria described above, only three of the 59 quadruple associations are interpreted as partially nonhomologous, the corresponding figures for associa-

Figure 3. Complete reconstruction of an early pachytene nucleus (number 19). Figure $3 a$ shows the chromosomes paired into bivalents while Figures $3 \mathrm{~b}-\mathrm{d}$ depict the remainder of the 112 chromosomes of the nucleus. For further explanation see Table $I$ and text. The chromosomes are numbered according to size, chromosome number 1 being the longest. $A$ and $B$ denotes two bivalents of similar length and $a, b, c$ and $d$ the individual chromosomes of trivalents + univalents, quadrivalents or nonhomologously paired chromosomes. 
Table I b

Lateral component length of the remainder of the chromosomes of nucleus 19. (See also Table I a and Figures 3 b - 3 d).

\begin{tabular}{|c|c|c|c|c|c|}
\hline \multicolumn{2}{|c|}{$\begin{array}{c}\text { Chromosome } \\
\text { number }\end{array}$} & \multirow{2}{*}{$\begin{array}{l}\begin{array}{c}\text { Lateral component } \\
\text { length }(\mu \mathrm{m})\end{array} \\
8.9\end{array}$} & \multicolumn{2}{|c|}{$\begin{array}{c}\text { Chromosome } \\
\text { number }\end{array}$} & \multirow{2}{*}{$\begin{array}{c}\begin{array}{c}\text { Lateral component } \\
\text { length }(\mu \mathrm{m})\end{array} \\
5.8\end{array}$} \\
\hline 1 & $\mathrm{a}$ & & 14 & $\mathrm{a}$ & \\
\hline & $\mathrm{b}$ & 8.8 & & $\mathrm{~b}$ & 5.0 \\
\hline & $\mathrm{c}$ & 7.8 & & c & 4.6 \\
\hline & d & 7.8 & & d & 5.3 \\
\hline \multirow[t]{4}{*}{2} & a & 7.3 & 15 & a & 4.9 \\
\hline & b & 7.0 & & $\mathrm{~b}$ & 5.2 \\
\hline & c & 8.1 & & $c$ & 5.3 \\
\hline & d & 7.5 & & $d$ & 5.5 \\
\hline \multirow[t]{4}{*}{3} & $\mathrm{a}$ & 8.3 & 16 & $\mathrm{a}$ & 5.4 \\
\hline & b & 7.2 & & $\mathrm{~b}$ & 5.0 \\
\hline & c & 8.4 & & c & 4.9 \\
\hline & d & 7.4 & & $\mathrm{~d}$ & 4.9 \\
\hline \multirow[t]{4}{*}{4} & a & 6.6 & 18 & $\mathrm{a}$ & 5.4 \\
\hline & $b$ & 7.3 & & $b$ & 5.2 \\
\hline & c & 6.7 & & c & 4.7 \\
\hline & d & 6.4 & & $d$ & 4.3 \\
\hline \multicolumn{2}{|c|}{$5 \mathrm{~A} \mathrm{a}$} & 6.2 & \multicolumn{2}{|c|}{$20 \mathrm{~B} \mathrm{a}$} & 4.3 \\
\hline & b & 7.4 & & $\mathrm{~b}$ & 5.3 \\
\hline \multirow[t]{4}{*}{7} & $\mathrm{a}$ & 6.0 & \multirow[t]{4}{*}{21} & a & 4.9 \\
\hline & $\mathrm{b}$ & 6.2 & & $\mathrm{~b}$ & 4.8 \\
\hline & c & 6.0 & & $c$ & 4.7 \\
\hline & d & 7.1 & & $d$ & 4.3 \\
\hline \multirow[t]{4}{*}{9} & a & 5.6 & \multirow[t]{4}{*}{26} & $\mathrm{a}$ & 3.9 \\
\hline & $b$ & 6.1 & & $b$ & 3.6 \\
\hline & c & 6.3 & & $\mathrm{c}$ & 4.0 \\
\hline & d & 5.5 & & d & 3.4 \\
\hline \multirow[t]{4}{*}{11} & a & 5.6 & \multicolumn{2}{|c|}{$28 \mathrm{~A} \mathrm{a}$} & 3.4 \\
\hline & b & 5.0 & & $\mathrm{~b}$ & 3.6 \\
\hline & c & 6.0 & & & \\
\hline & d & 5.3 & & & \\
\hline
\end{tabular}

tions of 3 chromosomes being 2 trivalents and 3 nonhomologous associations. As seen in Table III, the majority of the quadrivalents contain one point of pairing partner exchange and otherwise complete synaptonemal complexes. The quadrivalents numbered $3,9,11,14,15,16,18$ and 26 in Figure 3 are of this type. A shift of pairing partner is illustrated in a series of micrographs in Figures 6 and 7. Quadrivalents with 2 unpaired telomere regions (Table III, column 2) are also relatively frequent, (e.g., quadrivalents 2 and 7 in Figure 3). Two infrequent types of quadrivalents are characterized by two switches of pairing partner, resulting in six separate stretches of synaptonemal complex in one case and five stretches in the other. The latter type is illustrated by a series of micrographs in Figure 8 and a reconstruction in Figure 9. One association of four chromosomes with a short stretch of synaptonemal complex between one lateral com- 

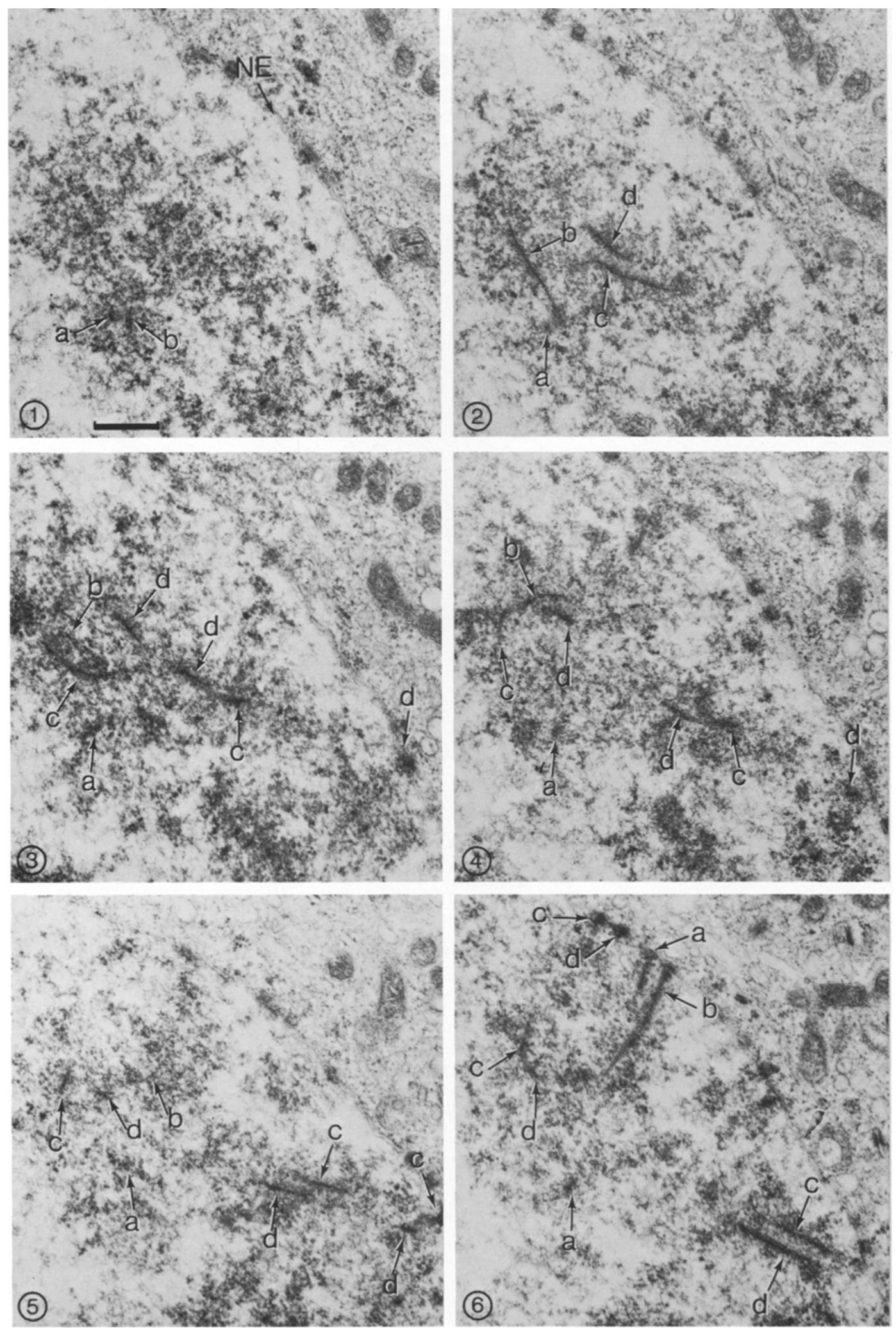

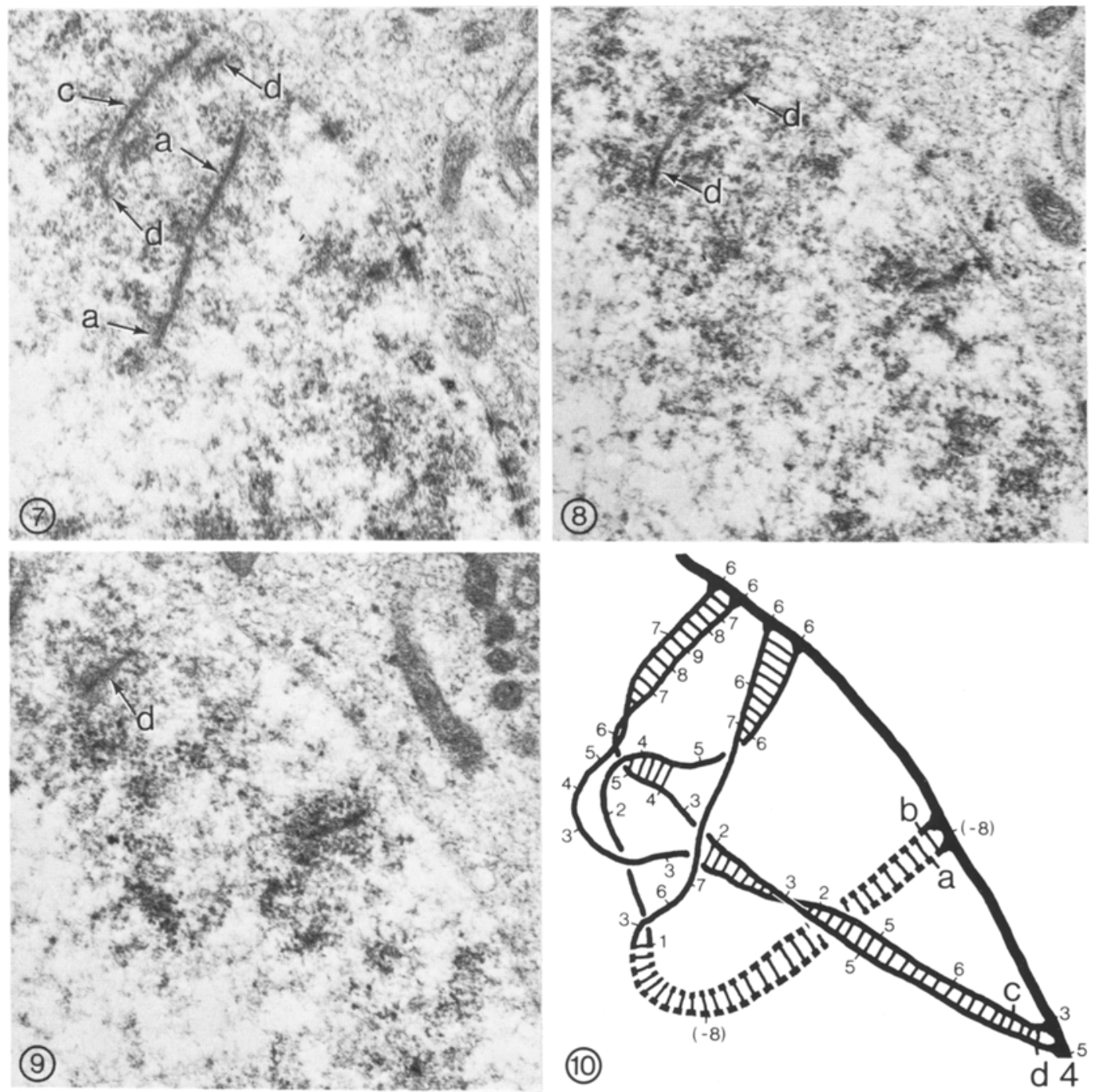

Figure 4. Nine consecutive sections of a partially nonhomologous association in a quadrivalent (chromosomes 21 , Figure 3c). A reconstruction of the lateral components and synaptonemal complexes is given in Figure 4.10, and a schematic drawing of the association in Figure 5. The two partially paired bivalents are interlocked and a short interstitial stretch of synaptonemal complex has formed in an anomalous way. In this complex one lateral component is inverted relative to the other signifying either nonhomologous pairing or heterozygosity for an inversion. The four chromosomes are denoted $\mathrm{a}, \mathrm{b}, \mathrm{c}$ and $\mathrm{d}$, respectively. NE, nuclear envelope. (Bar $=0.5 \mu \mathrm{m})$.

ponent and a completely paired bivalent was observed (Table III, column 5). The central region of one of the two stretches of synaptonemal complex appeared less distinct than that of completed complexes. The two trivalents observ- ed are characterized by one switch of pairing partner (e.g., chromosome 4 in Figure 3b).

Two different types of partially nonhomologous associations of four chromosomes were recognized. The first one involves two pairs of 
S. W. Rasmussen \& P. B. Holm: Chromosome pairing in Bombyx

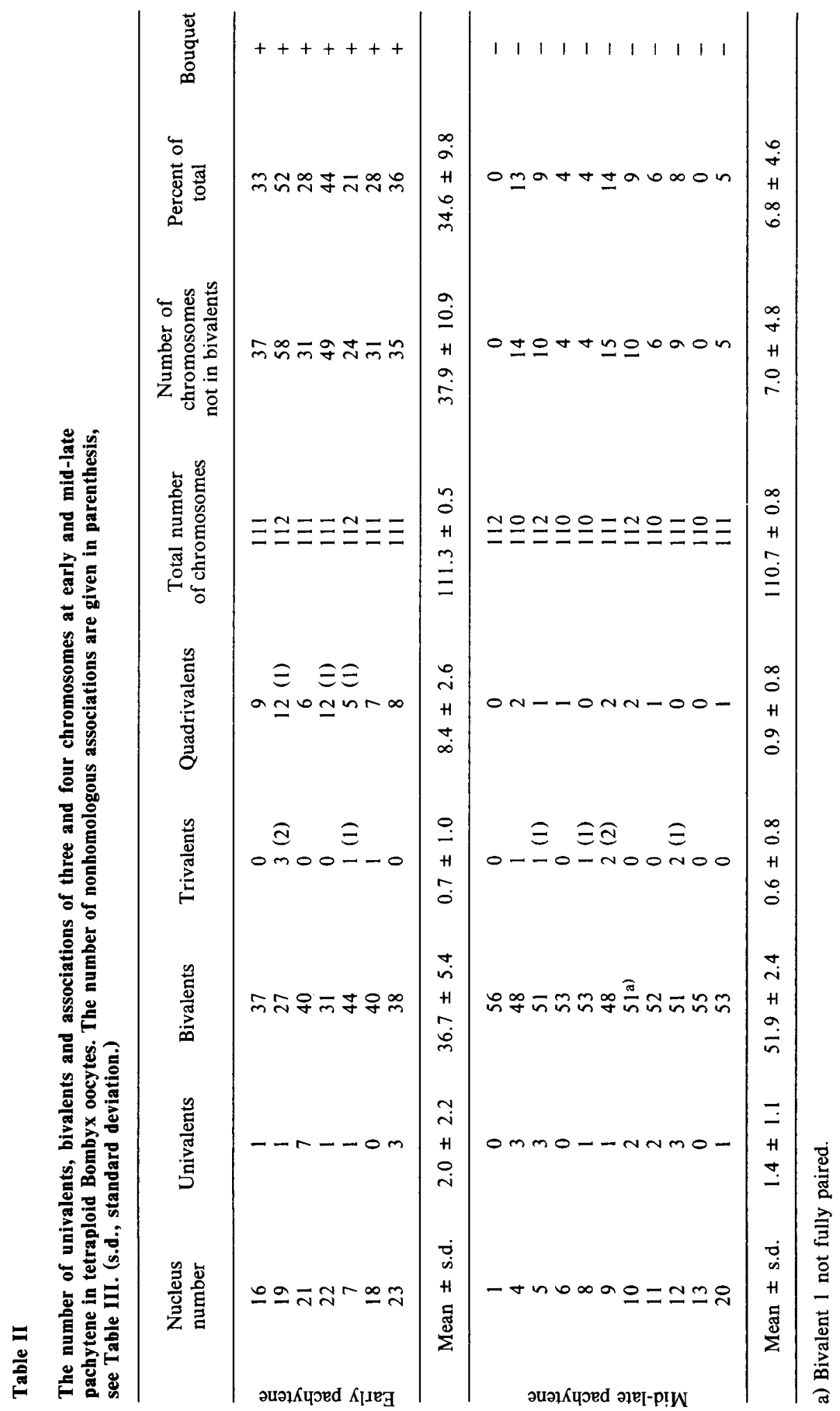


Table III

The different types of quadrivalents, trivalents and partially nonhomologous associations of three and four chromosomes at early and mid-late pachytene in tetraploid Bombyx oocytes (see also Table II).

\begin{tabular}{|c|c|c|c|c|c|c|c|c|c|c|c|c|}
\hline & & \multicolumn{7}{|c|}{ HOMOLOGOUS } & \multicolumn{4}{|c|}{ NONHOMOLOGOUS } \\
\hline 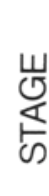 & 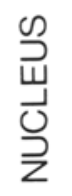 & $\ln _{n \rightarrow n}$ & $\prod_{n \rightarrow n}$ & "He & "ִ & $\prod_{n=n}$ & $\ln _{n}$ & I & & D. & & $\|_{n}$ \\
\hline \multirow{7}{*}{ 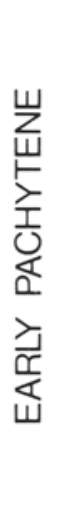 } & 16 & 6 & 2 & & 1 & & & 1 & & & & \\
\hline & 19 & 9 & 2 & & & & 1 & 1 & & 1 & 2 & \\
\hline & 21 & 5 & & 1 & & & & 7 & & & & \\
\hline & 22 & 5 & 4 & & 2 & & & 1 & 1 & & & \\
\hline & 7 & 4 & & & & & & 1 & 1 & & & 1 \\
\hline & 18 & 6 & 1 & & & & 1 & & & & & \\
\hline & 23 & 4 & 1 & & 2 & 1 & & 3 & & & & \\
\hline \multirow{11}{*}{ 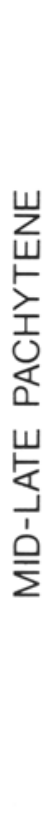 } & 1 & & & & & & & & & & & \\
\hline & 4 & 2 & & & & & 1 & 3 & & & & \\
\hline & 5 & 1 & & & & & & 3 & & & 1 & \\
\hline & 6 & 1 & & & & & & & & & & \\
\hline & 8 & & & & & & & 1 & & & 1 & \\
\hline & 9 & 2 & & & & & & 1 & & & 2 & \\
\hline & 10 & 2 & & & & & & 2 & & & & \\
\hline & 11 & 1 & & & & & & 2 & & & & \\
\hline & 12 & & & & & & 1 & 3 & & & 1 & \\
\hline & 13 & & & & & & & & & & & \\
\hline & 20 & 1 & & & & & & 1 & & & & \\
\hline
\end{tabular}


S. W. Rasmussen \& P. B. Holm: Chromosome pairing in Bombyx

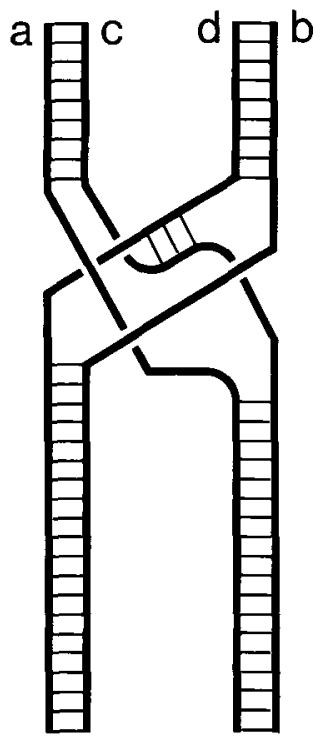

5

Figure 5. Diagram illustrating the pairing of chromosomes 21 in nucleus 19 (see also Figures $3 \mathrm{c}$ and 4 and Table Ib) with the short, interstitial synaptonemal complex mediating presumably nonhomologous pairing.

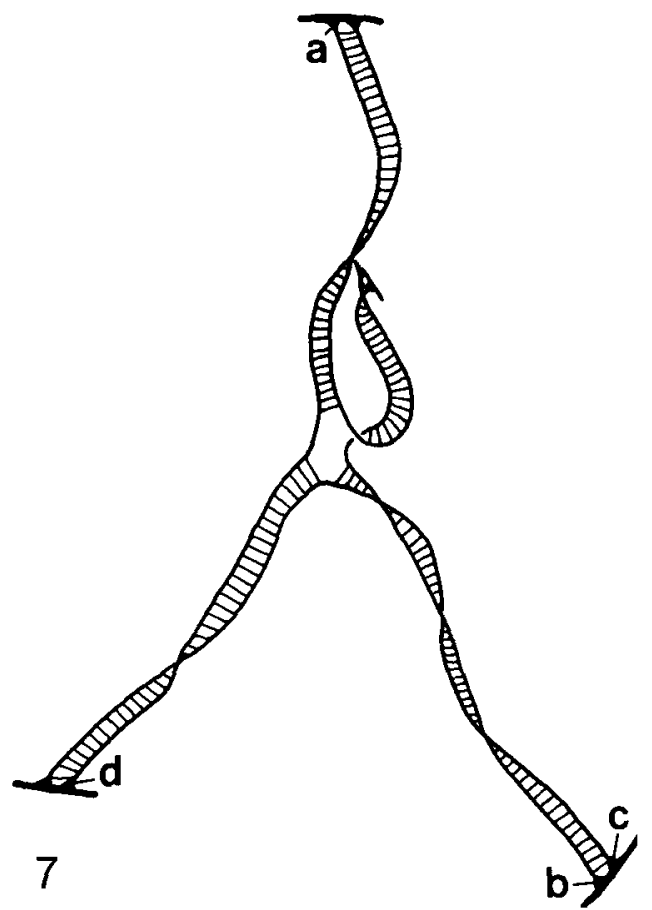

Figure 7. Reconstruction of a quadrivalent (nucleus number 23). Synaptonemal complex formation is complete outside the region of pairing partner exchange (see Table III and Figure 6). homologues of different length (Table III, column 8) with one switch of pairing partner. The second type (Table III, column 9) involves four homologues with an interstitially nonhomologously paired segment, and has been described above (chromosomes 21, Figure 3c). Partially nonhomologous associations of three chromosomes are organized into $Y$ shaped configurations and consist of 2 homologous and one nonhomologous chromosomes (Table III, column 10). Incomplete pairing in such a triple association leads to the configurations listed in the last column of Table III.

\subsubsection{Mid-late pachytene}

The transition from early to mid pachytene is characterized by a major change in the internal organization of the nucleus (Figure 10). The bouquet configuration can no longer be recognized, the attachment sites of the telomeres being evenly distributed throughout the inner membrane of the nuclear envelope. Towards the end of pachytene, the telomeres are free in the nucleoplasm. In tetraploid Bombyx oocytes, the resolution of the chromosome bouquet is accompanied by a drastic increase in the number of bivalents. On the average, only 7 chromosomes

Figure 6. Five consecutive sections of the shifts of pairing partners in a quadrivalent. A reconstruction of the lateral components and synaptonemal complexes is given in Figure 6.6 and the entire quadrivalent in Figure 7. The four chromosomes of the quadrivalent are denoted by a, b, c and d, respectively. $($ Bar $=0.5 \mu \mathrm{m})$. 

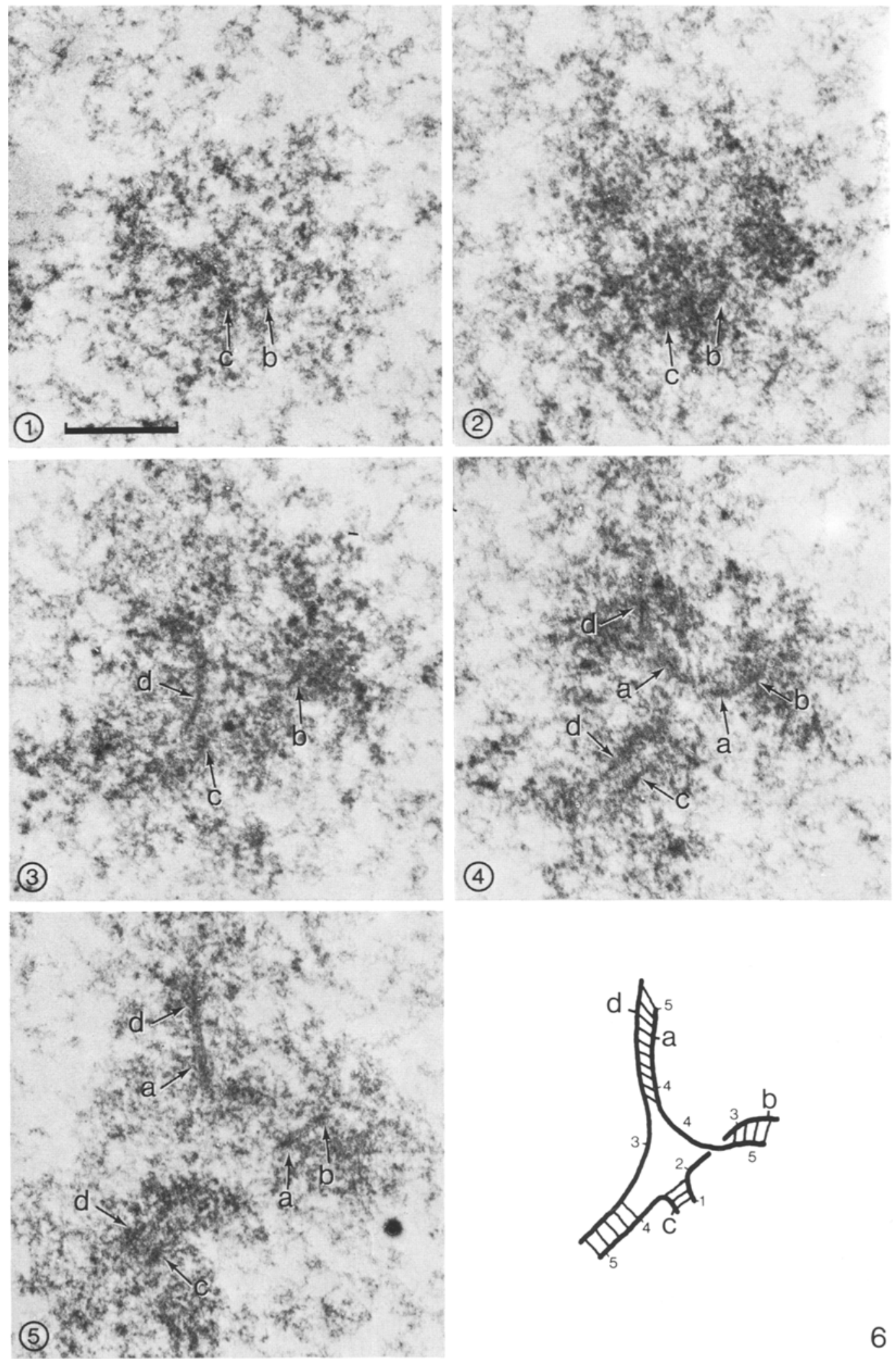

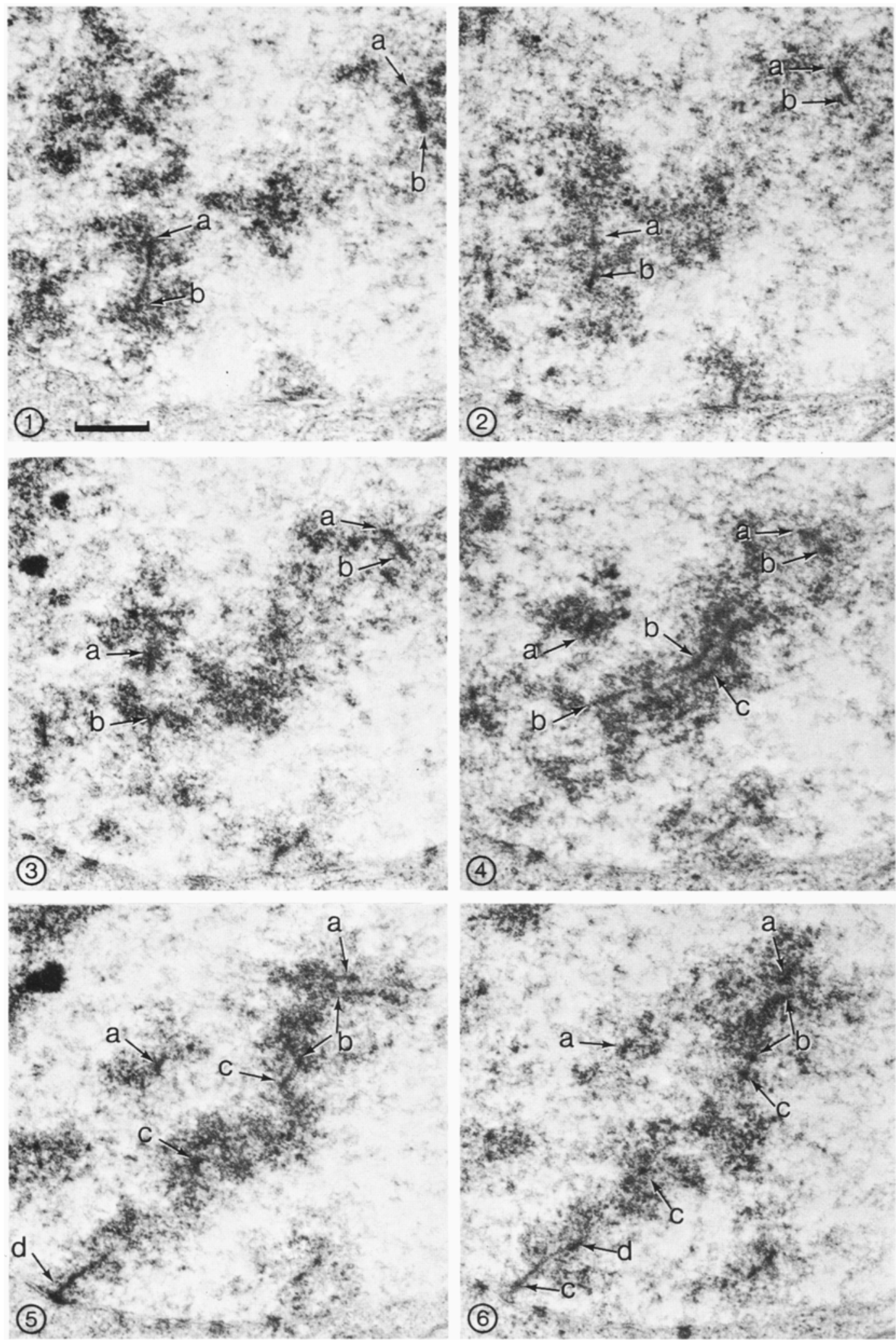

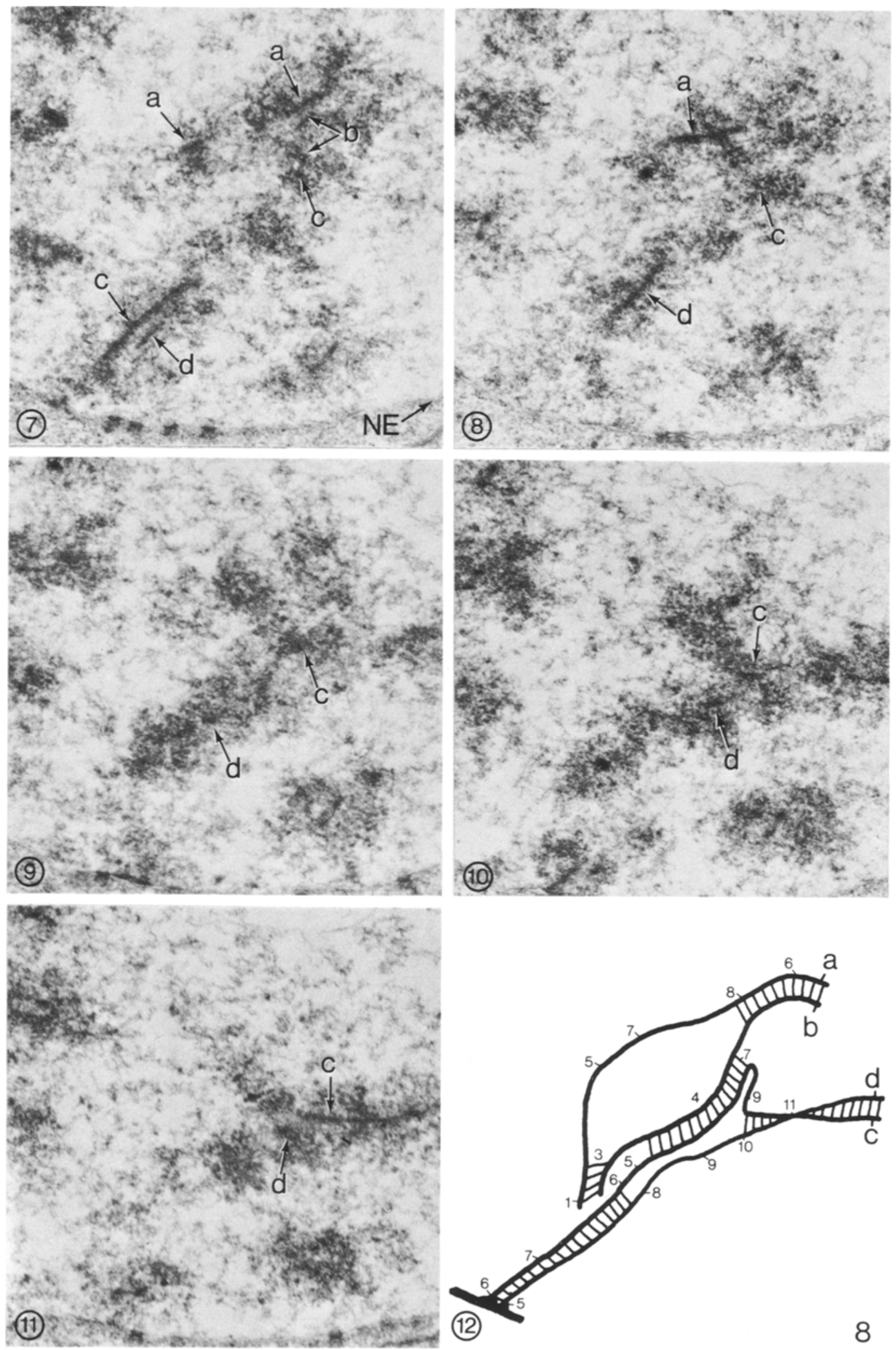
Figure 8. Eleven consecutive sections of a quadrivalent (nucleus number 23, Table III). The four chromosomes are denoted by a, b, c and d, respectively. Chromosomes b and $d$ switch pairing partner twice. A reconstruction of the lateral components and synaptonemal complexes is given in Figure 8.12. The entire quadrivalent is shown in Figure 9. NE, nuclear envelope. (Bar $=0.5 \mu \mathrm{m}$ ).

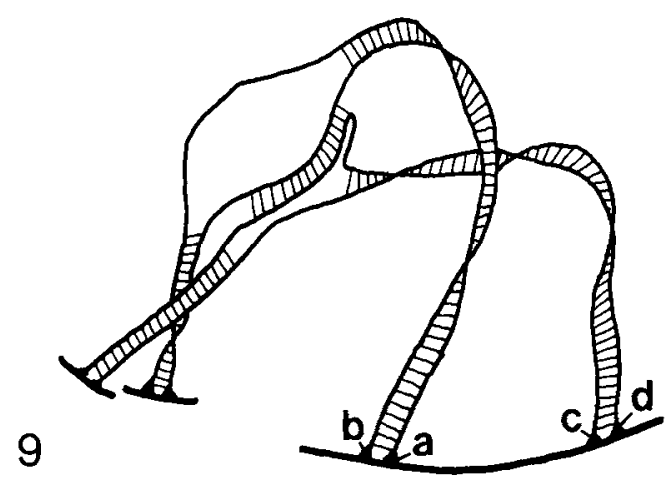

Figure 9. Reconstruction of a quadrivalent with two switches of pairing partner. The same quadrivalent is depicted in Figure 8. are not paired into bivalents compared to a value of 38 at early pachytene. This increase coincides with a decrease in the number of quadrivalents while the number of univalents and triple associations are about the same at the two stages. The quadrivalents are thus reorganized into bivalents by dissolution and reassembly of synaptonemal complexes during the transition from early to mid pachytene, the reorganization probably going to completion by late pachytene.

The drastic change in the pairing pattern from early to mid-late pachytene is also illustrated by the data in Table IV. At early pachytene, the total length of all lateral components is $601 \pm$ $17 \mu \mathrm{m}$ compared to $532 \pm 69 \mu \mathrm{m}$ at mid-late pachytene. The lateral component length of chromosomes not paired into bivalents amount-

\section{Table IV}

Total length of the lateral components in 7 early and 11 mid-late pachytene nuclei of tetraploid Bombyx oocytes. (s.d., standard deviation).

\begin{tabular}{|c|c|c|c|c|}
\hline & $\begin{array}{l}\text { Nucleus } \\
\text { number }\end{array}$ & $\begin{array}{l}\text { Lateral component } \\
\text { length of bivalents }(\mu \mathrm{m})\end{array}$ & $\begin{array}{l}\text { Lateral component } \\
\text { length of chromosomes } \\
\text { not paired into } \\
\text { bivalents }(\mu \mathrm{m})\end{array}$ & $\begin{array}{c}\text { Total length } \\
\text { of lateral } \\
\text { components }(\mu \mathrm{m})\end{array}$ \\
\hline \multirow{8}{*}{ 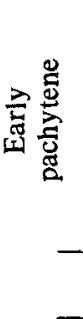 } & 16 & 391 & 214 & 605 \\
\hline & 19 & 267 & 338 & 605 \\
\hline & 21 & 418 & 186 & 604 \\
\hline & 22 & 307 & 271 & 578 \\
\hline & 7 & 484 & 150 & 634 \\
\hline & 18 & 407 & 185 & 592 \\
\hline & 23 & 397 & 191 & 588 \\
\hline & Mean \pm s.d. & $382 \pm 67$ & $219 \pm 59$ & $601 \pm 17$ \\
\hline \multirow{12}{*}{ 离 } & 1 & 464 & 0 & 464 \\
\hline & 4 & 433 & 63 & 496 \\
\hline & 5 & 601 & 52 & 653 \\
\hline & 6 & 604 & 28 & 632 \\
\hline & 8 & 595 & 22 & 617 \\
\hline & 9 & 442 & 81 & 523 \\
\hline & 10 & 394 & 59 & 453 \\
\hline & 11 & 484 & 25 & 509 \\
\hline & 12 & 440 & 38 & 478 \\
\hline & 13 & 472 & 0 & 472 \\
\hline & 20 & 519 & 38 & 557 \\
\hline & Mean \pm s.d. & $495 \pm 71$ & $37 \pm 24$ & $532 \pm 69$ \\
\hline
\end{tabular}




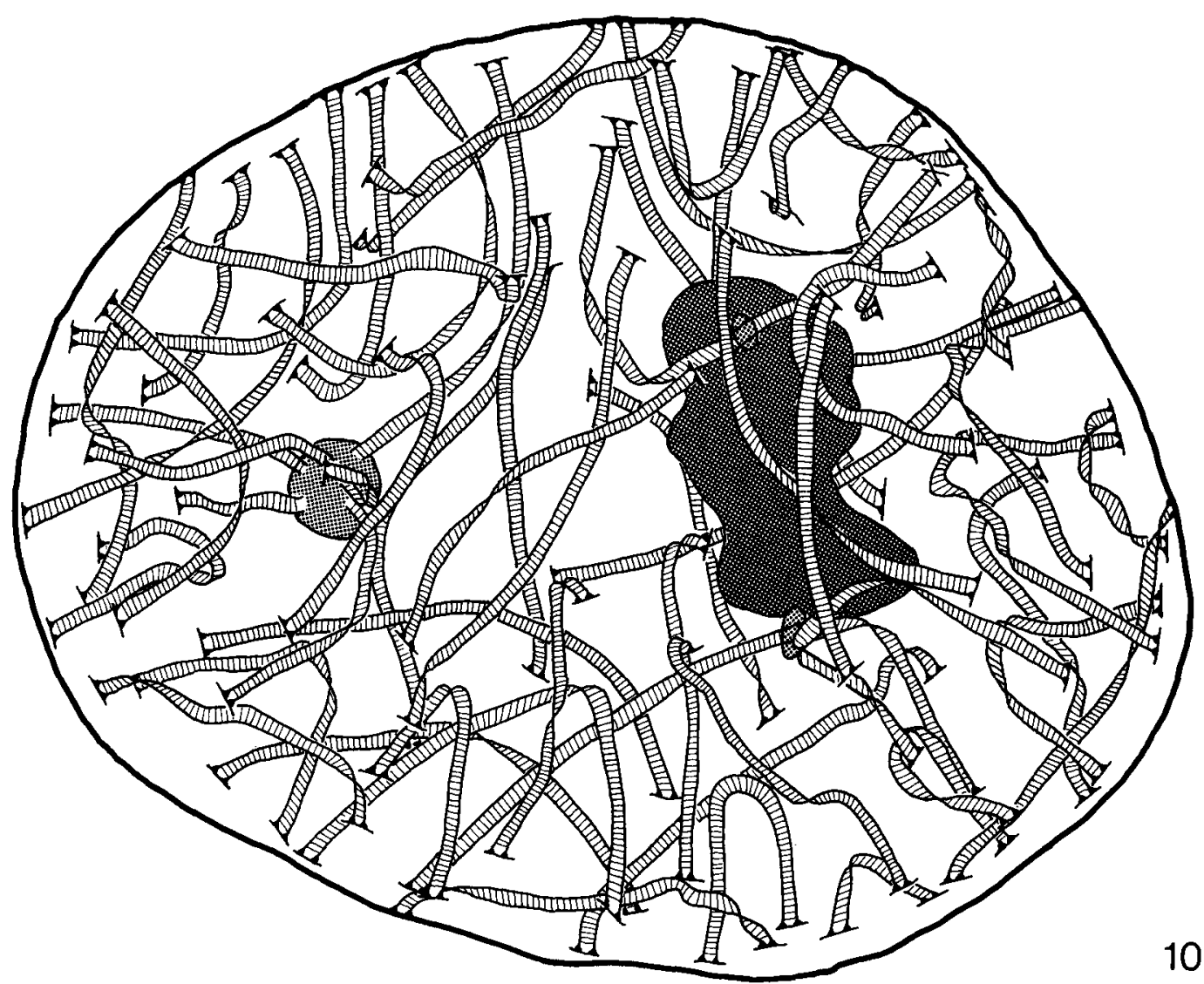

Figure 10. Complete reconstruction of a mid pachytene nucleus (number 13). 55 bivalents are present and all the telomeres are attached to the nuclear envelope. The knobs on bivalent I have fused and the synaptonemal complexes of both bivalents are discontinuous inside the knob. It is thus uncertain whether the four chromosomes form a quadrivalent.

ed to $219 \pm 59 \mu \mathrm{m}$ at early pachytene, whereas at mid-late pachytene this value has decreased to $37 \pm 24 \mu \mathrm{m}$.

\subsubsection{Chromosome length and chromosome pai- ring}

The correlation between chromosome length and the frequency at which chromosomes are present as univalents or multiple associations other than bivalents is shown in Table V. At early pachytene, the frequencies of such associations, predominantly quadrivalents, increase nearly proportionally with chromosome length. The chromosomes in the classes from $8-10 \mu \mathrm{m}$ are mainly chromosomes 1 and 2 which, as seen in Table $\mathrm{V}$, form quadrivalents in $78 \%$ and
$43 \%$ of the nuclei, respectively. Similar correlations between chromosome length and frequency of quadrivalent formation have been demonstrated repeatedly in autotetraploid species by light microscopical studies of diplotene-metaphase I nuclei $(6,16)$.

The mean, total lateral component lengths of di-, tri- and tetraploid oocytes and of diploid spermatocytes are given in Table VI. These data show that an increase in ploidy level is not accompanied by a comparable increase of the total length of the lateral components as is the case in di- and tetraploid yeast (2). In the diploid Bombyx oocytes, the lateral component length for the individual genome at early pachytene is $196 \mu \mathrm{m}$, that for triploid oocytes $137 \mu \mathrm{m}$ and 
Table V

The relationship between the length of the chromosomes in tetraploid Bombyx oocytes and the frequencies of chromosomes not paired into bivalents. The chromosomes of 7 early pachytene and 11 mid-late pachytene nuclei were devided into 10 classes of increasing length. The percentage of chromosomes not paired into bivalents was determined for each class.

\begin{tabular}{ccc}
\hline & $\begin{array}{c}\text { Length of } \\
\text { lateral components } \\
(\mu \mathrm{m})\end{array}$ & \multicolumn{2}{c}{$\begin{array}{c}\text { Frequency of chromosomes } \\
\text { not paired into bivalents }(\%)\end{array}$} & Mid-late pachytene \\
\cline { 2 - 3 } & Early pachytene & 0 \\
$0-1$ & 0 & 20 \\
$1-2$ & 0 & 12 \\
$2-3$ & 0 & 4 \\
$3-4$ & 14 & 6 \\
$4-5$ & 25 & 9 \\
$5-6$ & 36 & 7 \\
$6-7$ & 45 & 29 \\
$7-8$ & 37 & 0 \\
$8-9$ & 63 & 23 \\
$9-10$ & 80 & 0 \\
\hline
\end{tabular}

that for tetraploid oocytes $150 \mu \mathrm{m}$. At mid-late pachytene, the corresponding values are 212 $(2 n), 171(3 n)$ and $133(4 n)$. The relatively shorter chromosomes of tetraploid oocytes may favor chromosome pairing and synaptonemal complex formation starting from one end only, the pairing in most cases being completed before a second site for complex formation at the opposite end is established. This may in part explain the difference in the number of interlockings found at late zygotene-early pachytene in diploid oocytes ( 3 out of 4 nuclei possessing one or more interlockings) and in tetraploid oocytes (one interlocking in 7 early pachytene nuclei). It may also in part explain that more bivalents are observed than might be expected if synaptonemal complex formation simultaneously is initiated from both ends and if all four homologous telomeres have an equal probability for initiating a complex. When a synaptonemal complex has been initiated between two homologous telomeres, the probability for a second initiation site at the other ends of the same chromosomes is 0.17 . On these assumptions, the expected number of

Table VI

Total lateral component length $(\mu \mathrm{m})$ in diploid, triploid and tetraploid oocytes and diploid spermatocytes at early and mid-late pachytene. ( $N$, number of nuclei, s.d., standard deviation.)

\begin{tabular}{|c|c|c|c|c|c|c|c|c|}
\hline \multirow{2}{*}{ Stage } & \multicolumn{2}{|r|}{ Male $2 n^{a}$} & \multicolumn{2}{|r|}{ Female $2 n^{b}$} & \multicolumn{2}{|r|}{ Female $3 n^{c}$} & \multicolumn{2}{|r|}{ Female 4n } \\
\hline & $\mathbf{N}$ & Length \pm s.t. & $\mathrm{N}$ & Length \pm s.d. & $\mathrm{N}$ & Length \pm s.d. & $\mathrm{N}$ & Length \pm s.d. \\
\hline Early pachytene & 6 & $395 \pm 23$ & 4 & $391 \pm 30$ & 4 & $411 \pm 41$ & 7 & $601 \pm 17$ \\
\hline Mid-late pachytene & 4 & $551 \pm 22$ & 6 & $424 \pm 14$ & 7 & $514 \pm 28$ & 11 & $532 \pm 69$ \\
\hline
\end{tabular}

a) unpublished observations

b) data from RASMUSSEN (22)

c) data from RASMUSSEN (24) 
bivalents per nucleus is 9.3 , whereas 36.7 have been observed.

In contrast, the frequency of quadrivalents involving the long chromosomes 1 and 2 is closer to that expected on the above assumptions. For chromosome 2 quadrivalents were found in $43 \%$ of the nuclei against an expectation of $83 \%$. For chromosome 1, a value of $78 \%$ quadrivalents is found which is close to expectation. This possibly reflects the longer duration of the pairing, whereby the probability for synaptonemal complex formation from both ends is increased. The very high frequency of quadrivalents involving chromosomes 1 and the fact that the switch of pairing partner in most cases occurs within the knob furthermore indicates that the knob impedes synaptonemal complex formation promoting initiation from both ends of the chromosomes. A similar effect of condensed chromatin has been noted in human spermatocytes (25) where the rate of synaptonemal complex formation is retarded in the centromere region while in the secondary constrictions of bivalents 1,9 and 16 synaptonemal complex formation is delayed until mid pachytene.

At mid pachytene, correlation between chromosome length and quadrivalent formation is less pronounced possibly due to the low number of chromosomes not paired into bivalents. Chromosomes 1 are, however, still present as a quadrivalent in $23 \%$ of the nuclei while all quadrivalents of chromosomes 2 are resolved and repaired into bivalents.

\section{DISCUSSION}

\subsection{General aspects}

Crossing over and chiasma formation are lacking in females of Bombyx mori (18, 29, 30). Through the analysis of the meiotic prophase in diploid oocytes from leptotene to anaphase I, it has been shown $(22,23)$ that the lack of chiasmata is compensated for by the retention and ultrastructural modification of the synaptonemal complex whereby the co-orientation of the two homologues of a bivalent is preserved up to anaphase $\mathrm{I}$.

In Bombyx spermatocytes where crossing over and chiasma formation take place $(18,29)$, recombination nodules are readily identified at early pachytene (Holm and RASMUSSEN, unpublished observations). The absence of recombination nodules in Bombyx oocytes thus provides additional support for the proposal by CARPENTER (5) that the nodules are essential structures in the crossing over process. It is conceivable that the absence of nodules in oocytes is somehow related to the smaller diameter of the central region of the synaptonemal complex, the width being 70-80 nm compared to a width of $100 \mathrm{~nm}$ in males. The difference in width may result from a change in one or more of the constituents of the central region in oocytes whereby the binding of the nodules to the central region could be prevented.

\subsection{Chromosome pairing}

The drastic reduction of the number of multivalents between early and mid pachytene in tetraploid as well as in triploid Bombyx oocytes clearly shows that the initial chromosome pairing and synaptonemal complex formation in zygotene is followed by a turnover of synaptonemal complexes which tends to optimize pairing in the form of bivalents. The low number of univalents present throughout pachytene in tetraploid oocytes indicates that the dissolution of the central region of the complex is immediately succeeded by formation of a new central region between a different combination of lateral components. This ultimately results in completely paired bivalents. At metaphase I in tetraploid oocytes only bivalents are observed by light microscopy and the resulting eggs are fully balanced and produce viable offspring (1).

In the absence of crossing over and chiasma formation, chromosome pairing and synaptonemal complex formation thus consist of two distinct phases: A specific zygotene pairing with very high preference for synaptonemal complex formation between homologous chromosome regions and a correction of irregularities in this pairing by dissolution of the central region of the complex succeeded by or coinciding with a second round of pairing and synaptonemal complex formation. The results from triploid oocytes have furthermore shown that this second round of pairing is not dependent upon homology of the chromosomes or chromosome regions to be paired. 
In contrast to oocytes tetraploid spermatocytes at metaphase I contain 0.45 univalents (range 04), 42.15 bivalents (range 34-56), 0.05 trivalents (range 0-1) and 6.7 quadrivalents (range $0-$ 10) according to KaWAGUCHI (17). These numbers are about the same as those observed at early pachytene in oocytes. Since crossing over and chiasma formation take place in spermatocytes this preservation of quadrivalents up to metaphase I indicates that the correction process is impeded when crossing over occurs.

As the differences in the pairing pattern observed between early and mid pachytene in human translocation heterozygotes (14) and mice inversion and duplication heterozygotes (21) are readily explained by the two phase pairing process we consider it a regular feature of the meiotic prophase.

The possibility for correction and successive nonspecific synaptonemal complex formation then depend on whether or not crossing over has stabilized the homologous pairing in a given bivalent segment.

In diploid organisms with normal levels of crossing over, the effect of the correction process and the nonspecific, second round of pairing is most clearly revealed in inversion, duplication and translocation heterozygotes. Gillies (9) reported in maize, heterozygous for an inversion on chromosome 3, that typical inversion loops and nonhomologous pairing were equally frequent. Moses (21) also observed strict homologous synaptonemal complex formation at early pachytene and nonhomologous complex formation at late pachytene in mice heterozygous for a duplication or an inversion. The striking correlation between the frequency of homologous loop pairing and the number of crossovers within an inverted segment of an inversion heterozygote of maize (inversion $1 \mathrm{Lh}$ in chromosome 1) reported by MAGuire (19) finds its explanation by the two phase pairing system. She observed that the frequency of inversion loops at pachytene (33.7\%) corresponds to $33.2 \%$ of crossing over in the inversion loop as judged by the frequency of anaphase I bridges and fragments. Only those inversion loops in which crossing over has occurred are preserved and thus identifiable by light microscopy while those loops in which crossing over has not occurred are reorganized into nonhomologously paired straight regions by dissolution and reassembly of the synaptonemal complex. Also failure of homologous pairing in the inverted segment at zygotene will lead to nonhomologous pairing with a synaptonemal complex at mid pachytene. The genetic control mechanisms for avoiding chiasma formation between homoeologous chromosomes operative in hexaploid wheat $(27,28)$, Avena (15) and Festuca (15) may also involve the two phase pairing system.

\section{ACKNOWLEDGEMENTS}

It is a pleasure to acknowledge the generous help and advice of the late professor B. L. AsTAUROV and Dr. V. N. VereISKAYA, Institute of Developmental Biology, Academy of Sciences USSR, Moscow. We also wish to thank JEAN Sage, AnN-sofi Steinholtz, Nina Rasmussen, Lena Kongsrud and Hanne Nielsen for their expert technical assistance. Finally, we are indebted to professor D. von WETTSTEIN for his critical review of the manuscript and for many valuable discussions during the course of the work. The work was supported by the cultural exchange program between USSR and Denmark and by grant 202-76-1 BIO DK from the Commission of the European Communities.

\section{REFERENCES}

1. Astaurov, B. L.: Experimental alterations of the developmental cytogenetic mechanisms in mulberry silkworms. Artificial parthenogenesis, polyploidy, gynogenesis, and androgenesis. Adv. Morphogenesis 6, 199-257 (1967)

2. Byers, B. \& L. GoETSCH: Electron microscopic observations on the meiotic karyotype of diploid and tetraploid Saccharomyces cerevisiae. Proc. Nat. Acad. Sci. USA 72, 5056-5060 (1975)

3. Brown, W. V. \& S. M. StaCK: Somatic pairing as a regular preliminary to meiosis. Bull. Torrey Bot. Club 95, 369-378 (1968)

4. Carmi, P., P. B. Holm, Y. Koltin, S. W. RasMUSSEN, J. SAGE, \& D. ZickLeR: The pachytene karyotype of Schizophyllum commune analyzed by three dimensional reconstruction of synaptonemal complexes. Carlsberg Res. Commun. 43, 117-132(1978)

5. CaRpenter, A. T. C.: Electron microscopy of meiosis in Drosophila melanogaster females: II: The recombination nodule - a recombination- 
associated structure at pachytene? Proc. Nat. Acad. Sci. USA 72, 3186-3189 (1975)

6. Darlington, C. D.: Recent advances in cytology. 2nd ed. Churchill, London $671 \mathrm{pp}$ (1937)

7. Feldman, M.: The effect of chromosomes 5B, SD, and 5A on chromosomal pairing in Triticum aestivum. Proc. Nat. Acad. Sci. USA 55, 14471453 (1966)

8. Fletcher, H. L. \& G. M. Hewitt: Nonhomologous synaptonemal complex formation in a heteromorphic bivalent in Keyacris scurra (Morabinae, Orthoptera). Chromosoma (Berl.) $65,271-281(1978)$

9. Giluies, C. B.: Ultrastructural analysis of maize pachytene karyotypes by three dimensional reconstruction of the synaptonemal complexes. Chromosoma (Berl.) 43, 145-176 (1973)

10. Giluies, C. B.: The nature and extent of synaptonemal complex formation in haploid barley. Chromosoma (Berl.) 48, 441-453 (1974)

11. Gilues, C. B.: An ultrastructural analysis of chromosomal pairing in maize. Compt. Rend. Trav. Lab. Carlsberg 40, 135-161 (1975)

12. Holm, P. B.: Three-dimensional reconstruction of chromosome pairing during the zygotene stage of meiosis in Lilium longiflorum (Thunb.) Carlsberg Res. Commun. 42, 103-151 (1977)

13. Holm, P. B. \& S. W. Rasmussen: Human meiosis 1. The human pachytene karyotype analyzed by three dimensional reconstruction of the synaptonemal complex. Carlsberg Res. Commun. 42, 283-323 (1977)

14. Holm, P. B. \& S. W. Rasmussen: Human meiosis III. Electron microscopical analysis of chromosome pairing in an individual with a balanced translocation $46, \mathrm{XY}, \mathrm{t}(5 \mathrm{p}-; 22 \mathrm{p}+)$. Carlsberg Res. Commun. 43, 329-350 (1978)

15. JaUHAR, P. P.: Genetic regulation of diploid-like chromosome pairing in Avena. Theor. Appl. Genet. 49, 287-295 (1977)

16. JоHN, B. \& K. R. Lewis: The meiotic system. Protoplasmatologia 6 (1965) Springer-Verlag, Wien, New York.

17. Kawaguchi, E.: Der Einfluss der Eierbehandlung mit Zentrifugierung auf die Vererbung bei dem Seidenspinner. II. Zytologische Untersuchung bei den polyploiden Seidenspinnern. Cytologia (Tokyo) 9, 38-54 (1938)

18. MAEDA, T.: Chiasma studies in the silkworm Bombyx mori L. Japanese Jour. Genet. 15, $118-$ 127 (1939)

19. MAGUiRe, M. P.: The relationship of crossing over to chromosome synapsis in a short paracentric inversion. Genetics 53, 1071-1077 (1966)
20. Menzel, M. Y. \& J. M. Price: Fine structure of synapsed chromosomes in Fl Lycopersicon esculentum-Solanum lycopersicoides and its parents. Amer. J. Bot. 53, 1079-1086 (1966)

21. Moses, M. J.: Microspreading and the synaptonemal complex in cytogenetic studies. In: A. de la Chapelle \& M. Sorsa, eds., Chromosomes Today 6, 71-82 (1977)

22. Rasmussen, S. W.: The meiotic prophase in Bombyx mori females analyzed by three-dimensional reconstructions of synaptonemal complexes. Chromosoma (Berl.) 54, 245-293 (1976)

23. Rasmussen, S. W.: The transformation of the synaptonemal complex into the relimination chromatin « of Bombyx mori oocytes. Chromosoma (Berl.) 60, 205-221 (1977)

24. Rasmussen, S. W.: Chromosome pairing in triploid females of Bombyx mori analyzed by three dimensional reconstructions of synaptonemal complexes. Carlsberg Res. Commun. 42, 163-197 (1977)

25. Rasmussen, S. W. \& P. B. Holm: Human meiosis II. Chromosome pairing and recombination nodules in human spermatocytes. Carlsberg Res. Commun. 43, 275-327 (1978)

26. Rasmussen, S. W. \& P. B. Holm: Chromosome pairing and synaptonemal complex formation. In: Proceedings of the XIV International Congress of Genetics (in press).

27. RILEY, R. \& C. N. LAW: Genetic variation in chromosome pairing. Adv. Genet. 13, 57-114 (1965)

28. Sears, E. R.: Genetic control of chromosome pairing in wheat. Ann. Rev. Genet. 10, 31-51 (1976)

29. Sturtevant, A. H.: No crossing over in the female of the silkworm moth. Amer. Naturalist 49, 42-44 (1915)

30. Tazima, Y.: The genetics of the silkworm. Logos Press \& Academic Press, London 253 pp (1964)

31. Vereiskaya, V. N.: Meiosis in thermoactivated oocytes of Bombyx mori L. Ontogenez (Moscow) 4, 139-144 (1973)

32. Wettstein, D. von: The assembly of the synaptinemal complex. Phil. Trans. R. Soc. London B 277, 235-243 (1977)

33. ZICKLER, D.: Development of the synaptonemal complex and the "recombination nodules « during meiotic prophase in the seven bivalents of the fungus Sordaria macrospora Auersw. Chromosoma (Berl.) 61, 289-316 (1977) 